\title{
Development of a Medical Care Terminal for Efficient Monitoring of Bedridden Subjects
}

\author{
Filipe Pereira, ${ }^{1,2}$ Vítor Carvalho, ${ }^{1,3}$ Filomena Soares, ${ }^{1}$ José Machado, ${ }^{4}$ Karolina Bezerra, ${ }^{4}$ \\ Rui Silva, ${ }^{2}$ and Demétrio Matos ${ }^{3}$ \\ ${ }^{1}$ ALGORITMI Research Centre, Industrial Electronics Department, University of Minho, Campus of Azurém, \\ 4800-058 Guimarães, Portugal \\ ${ }^{2}$ Lusíada University, Largo Tinoco de Sousa, 4760-108 Vila Nova de Famalicão, Portugal \\ ${ }^{3}$ Polytechnic Institute of Cávado and Ave, Campus of IPCA, 4750-810 Barcelos, Portugal \\ ${ }^{4}$ MEtRICs Research Centre, Mechanical Engineering Department, University of Minho, Campus of Azurém, \\ 4800-058 Guimarães, Portugal \\ Correspondence should be addressed to Vítor Carvalho; vcarvalho@ipca.pt
}

Received 30 November 2015; Revised 13 April 2016; Accepted 14 April 2016

Academic Editor: İlker Bekir Topçu

Copyright ( 2016 Filipe Pereira et al. This is an open access article distributed under the Creative Commons Attribution License, which permits unrestricted use, distribution, and reproduction in any medium, provided the original work is properly cited.

\begin{abstract}
This work is developed in the context of Ambient Assisted Living (AAL) and has as main objective the development of a mechatronic system that allows the care of bedridden patients with ongoing medical care handled by a single person. The developed Medical Care Terminal (MCT) improves autonomy in home care, safety, comfort, and hygiene of bedridden patients. The MCT has six biomedical sensors and four environmental sensors. Data acquisition and processing is performed using Arduino and LabVIEW platforms, respectively. The proposed solution has, as main feature, its adaptability to the patient needs. One of the MCT functionalities is the remote access to the patient data through the web. The caregiver may request help from a specialist who sends back information in real time to perform first aid assistance. This device has a flexible configuration allowing a fast and cheap reconfiguration according the specific needs of the patient. The proposed mechatronic system intends to meet the needs of bedridden patients improving their quality of life, health, safety, and comfort, while enabling the remote monitoring of the patients.
\end{abstract}

\section{Introduction}

Bedridden patients are confined to live in bed due to illness or infirmity. This category of people requires additional care to avoid the formation of pressure ulcers due to the long periods of time in the same physical posture. The pressure applied to the skin causes a deprivation of blood in the pressed skin area. If the pressure remains too high in the same region for a couple of hours, skin tissues get damaged and may even die. Since the discomfort of these pressure ulcers, for the patients, is enormous and the costs of treatment are high, the prevention of pressure ulcers is of utmost importance [1-3].

Prevention starts with the use of special materials for mattresses and sheets. In addition, the patient must change position every two hours requiring the presence of health professionals $[4,5]$.
The available commercial articulated beds are very expensive. In Portugal, the prices are around $€ 5000$ [6] and have some limitations. There is not yet available commercial equipment that allows a single person to take care of bedridden patients (including sheets changing and bathing). Also, there is not yet available a system to allow collecting and registering the biomedical data of the patient, considering a fast and easy reconfiguration according to the specific needs of the patient.

The goal of this project is then the development of a mechatronic system to withdraw the patient from his/her bed for bathing and basic healthcare as well as the development of a Medical Care Terminal (MCT) to collect physiological data of the patient. The configuration of this system is flexible and it is possible to change it in a simple and cheap way.

The motivation of this work arises from the fact that we are facing an aging population that needs medical attention. 
The proposed mechatronic system for supporting bedridden people is to be applied at home, where the caregiver is, in most situations, a single and aged person (wife or husband of an aged couple). The equipment must then help/support the caregiver in his/her tasks.

The MCT, as a complement to the mechatronic system, should be able to collect the patient's biomedical data and environmental data. It will also be possible for the person who takes care of the disabled person to be remotely supported by a doctor or a nurse. Moreover, the data obtained by the biomedical and the environmental sensors can be recorded in a file in order to assess the patient's health condition [7].

The overall objective of the project is the development of a mechatronic system applicable to disabled patients who are bedridden for long periods of time.

In most situations, patients in this condition require the assistance of two people to fulfil their basic needs due to sensitivity caused by disease or even their debilitated body structure. This difficulty is today easily unsurpassable by health professionals who have acquired their training in handling techniques for bedridden patient, regardless of their weight and height. However, it is intended that the equipment is applicable at home, making it imperative that it should be used by a single (and sometimes aged) person.

The paper is divided, besides the Introduction, into the following sections: Commercial Systems, Theoretical Concepts: Biomedical Sensors Operation, Medical Care Terminal, Experimental Results, and Conclusions and Future Work.

\section{Commercial Systems}

The commercial systems (with remote or local access) to monitor the biomedical variables in bedridden patients are expensive and unaffordable for most families. Currently, the reference price is about $€ 8600$ [8]. The clinical bioPLUX is an innovative medical device for physiotherapy and rehabilitation developed by Plux [8] (Figure 1).

The system has a software GUI bioPLUX for muscle rehabilitation, which makes the intervention of a therapist more efficient. This software is a web-based application, being developed with html, css, and JavaScript, available also for Android. The device is based on a model of service delivery in two formats: @Clinics, to support the work carried out between the user and the physical therapist in the clinic, and @Home, to complement the work at home [8]. Another company that is at the forefront of this equipment is Value Technology Inc. [9] which has highly sophisticated systems that allow remotely controlling and monitoring the patient in real time (Figure 2). Note that this system costs approximately $€ 3000$ [9].

The major disadvantage of these systems lies in its unaffordable cost and the specialized knowledge the caregiver must have.

\section{Theoretical Concepts: Biomedical Sensors Operation}

The biomedical sensors measure variables that represent physiological signals and convert them into an electrical

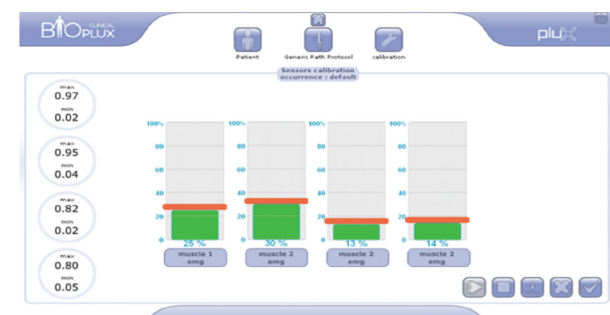

Figure 1: Terminal healthcare bioPLUX (MCT) [8].

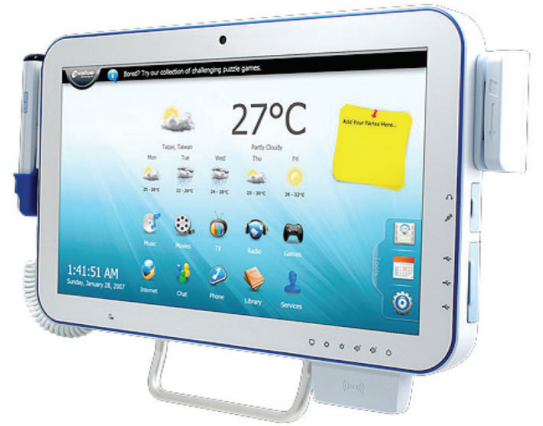

Figure 2: Terminal care of a Value Technology Inc. (MCT) [9].

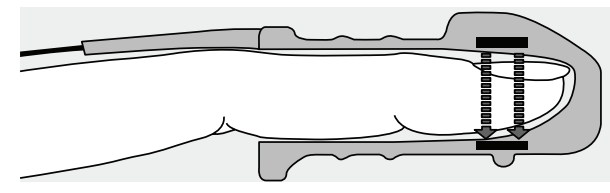

FIgURE 3: Probe oximetry [10].

signal. They are used in several biomedical applications [15]. In the following subsections, the principles of operation of some of the sensors used in the MCT are described.

3.1. Finger Oximeter. The Finger Oximeter sensor (Figure 3) is useful in any situation where the patient's oxygenation is unstable, including intensive care operations to evaluate recoveries of emergency oxygenation of the patient and determine the effectiveness or supplemental oxygen requirement [16].

Acceptable range of oxygenation is $95-99 \%$. Patients with values between 88 and $94 \%$ indicate that they may have a lack of oxygen in body tissues, caused by different factors (hypoxia); $100 \%$ values may indicate carbon monoxide poisoning [17].

The cause may be due to a change in any transport mechanism of oxygen, ranging from a physical obstruction of blood flow anywhere in the circulation (leading to loss of blood supply, known as ischemia) to anemia shift regions with low concentrations of oxygen in atmospheric air [10]. 

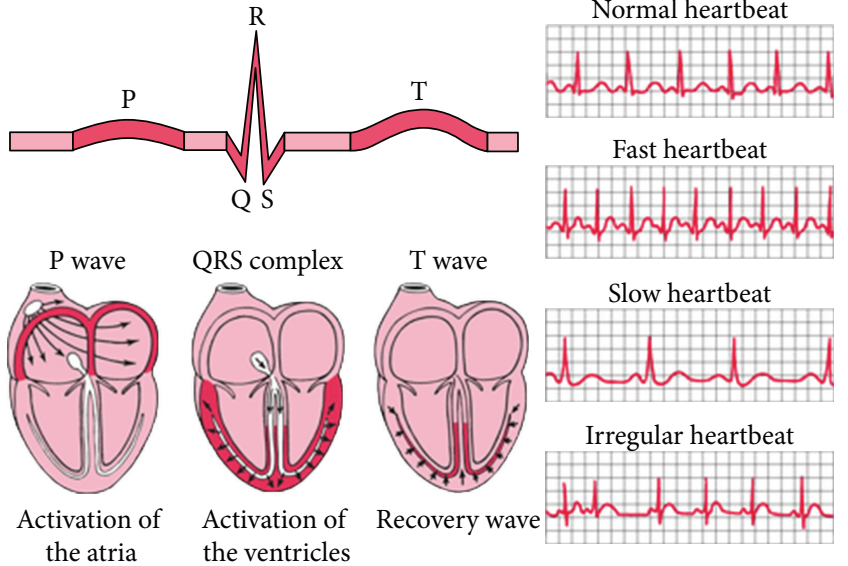

FIgURE 4: Activity of the heart in mediating an ECG [11].

3.2. Electrocardiogram (ECG) Signal. The electrocardiogram (ECG) is a health check in cardiology in which the record is made of the variation of the electrical potential generated by the electrical activity of the heart (Figure 4) [11, 18].

The ECG electrodes are connected to the body, while the patient lies on a bed. The accuracy of the ECG depends on the condition to be tested. A heart problem may not always appear in the ECG [19-21].

The following problems can be detected in the ECG:

(i) The orientation of the heart (as it is placed) in the thoracic cavity.

(ii) Evidence of increased thickness (hypertrophy) of the heart muscle.

(iii) Evidence of damage to the various parts of the heart muscle.

(iv) Evidence of interrupted blood flow to the heart damaging or destroying a portion of the heart muscle.

(v) Standard abnormal electrical activity that may predispose the patient to abnormal heart rhythm disorders.

(vi) The rate and mechanism underlying cardiac rhythm.

Typically, minor variations may occur. It is possible to perceive and record changes in heart rate or frequency. The normal frequency of heartbeats is 60 to 100 cycles (or beats per minute). In children, these numbers are usually higher [22-25].

3.3. Air Flow Sensor or Respiratory. Abnormalities and changes in respiratory rate are important indicators of physiological instability in many cases; the respiratory rate is an early indicator of this instability. Therefore, it is essential to monitor the respiratory rate as an indicator of the state of the patient. The airflow sensor may provide an early warning of hypoxia and apnea [12].

The nasal airflow sensor is a device used to measure the respiratory rate of a patient. This device consists of a flexible wire, which fits behind the ears, and a set of two pins, which are placed into the nostrils. These pipes measure the breath, as shown in Figure 5 [12].
TABLE 1: Body temperature under certain illness [12].

\begin{tabular}{lc}
\hline Hypothermia & $<35.0^{\circ} \mathrm{C}$ \\
& $\left(95.0^{\circ} \mathrm{F}\right)$ \\
\hline Normal & $36.5-37.5^{\circ} \mathrm{C}$ \\
& $\left(97.7-99.5^{\circ} \mathrm{F}\right)$ \\
\hline \multirow{2}{*}{ Fever or hyperthermia } & $>37.5-38.3^{\circ} \mathrm{C}$ \\
& $\left(99.5-100.9^{\circ} \mathrm{F}\right)$ \\
\hline \multirow{2}{*}{ Hyperpyrexia } & $>40.0-41.5^{\circ} \mathrm{C}$ \\
& $\left(104-106.7^{\circ} \mathrm{F}\right)$ \\
\hline
\end{tabular}

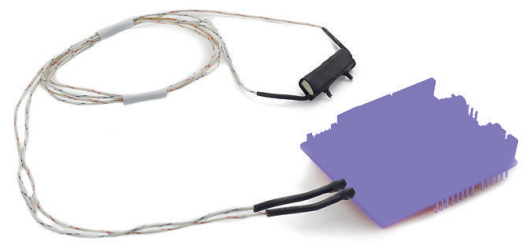

Figure 5: Airflow sensor (adapted from [12]).

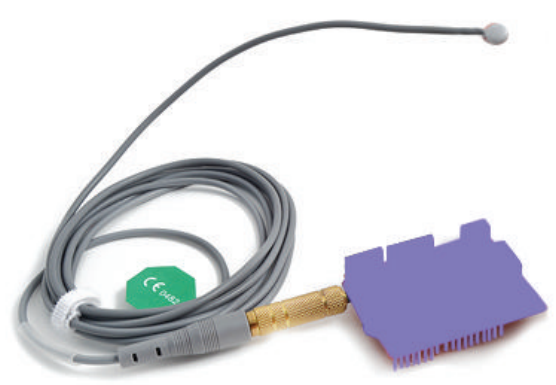

FIGURE 6: Body temperature sensor (adapted from [12]).

The cannula permits a "thermocouple" function, allowing accurately detecting changes in thermal airflow oral/nasal and nasal air temperature. This sensor is comfortably adjustable and easy to install. A normal human adult respiratory rate has a frequency of 15-30 breaths per minute [12].

3.4. Body Temperature Sensor. Body temperature depends on the location where the temperature acquisition is performed, the time of day, and the activity level of the person. Different parts of the body have different temperatures [12]. An example of a temperature sensor is shown in Figure 6.

Table 1 presents the values of the characteristic temperatures that a human body should possess under some circumstances [12].

3.5. Position Sensor or Acceleration. The position sensor is a type of motion sensor used to measure acceleration. In general, it has a degree of freedom relative to its own axis, and as it undergoes acceleration, the effect of inertia tends to keep the speed shifting relative to the axis. The magnitude of this displacement gives a measure of the acceleration. 


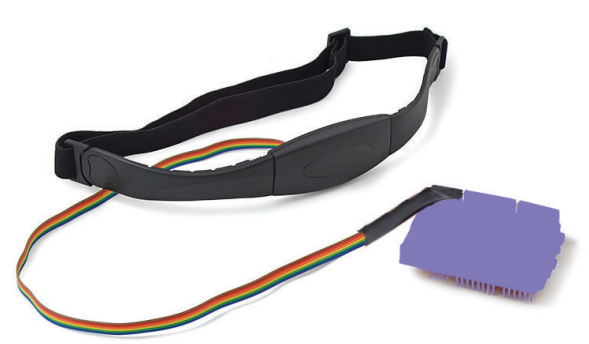

Figure 7: Position sensor (adapted from [12]).

It may also have a magnetometer, which is a type of motion sensor used to measure the intensity and direction of magnetic fields. The accelerometer and magnetometer may have a microcontroller in order to calculate the overall orientation of the individual.

The position sensor in Figure 7 (accelerometer) monitors five different patient positions (standing/sitting, supine, prone, left, and right) [12].

\section{Medical Care Terminal (MCT)}

In this section, the operation principle of the developed system, including the software and hardware development, is presented. In particular, the hardware system, the sensors used in the MCT, the software acquisition, and data processing as well as the remote communication system are detailed.

The user interface was developed in LabVIEW software and the reading of biomedical and environmental sensors was carried out at the Arduino platform.

In the first case, for each sensor there is a guide and a dedicated interface, where the real and the expected values are registered as well as the alarms. The values obtained by the sensors can be saved in an Excel file to allow further analysis.

4.1. System Hardware. In this paper, special emphasis is given to the MCT. The operation of this system optimizes the health of bedridden patients. The MCT has high quality biomedical sensors that perform the analysis in real time, through an integrated system that enables operation of biomedical sensors [12]. Figure 8 presents the MCT and the mechatronic system for bedridden patients $[13,14]$.

The MCT system is based on the E-Health Kit from Cooking Hacks [14]. It includes the biomedical monitoring system, the environmental data acquisition, and the remote platform. The block diagram of the system hardware is described in Figure 9 [14].

The biomedical monitoring system supports nine different sensors: pulse, oxygen in blood $\left(\mathrm{S}_{\mathrm{P}} \mathrm{O}_{2}\right)$, airflow (breathing), body temperature, electrocardiogram (ECG), blood glucose meter, galvanic skin response (GSR), blood pressure (sphygmomanometer), and the patient's position in bed (accelerometer), Figure 10 [12].

Regarding the environmental variables, the system has available the following sensors available:

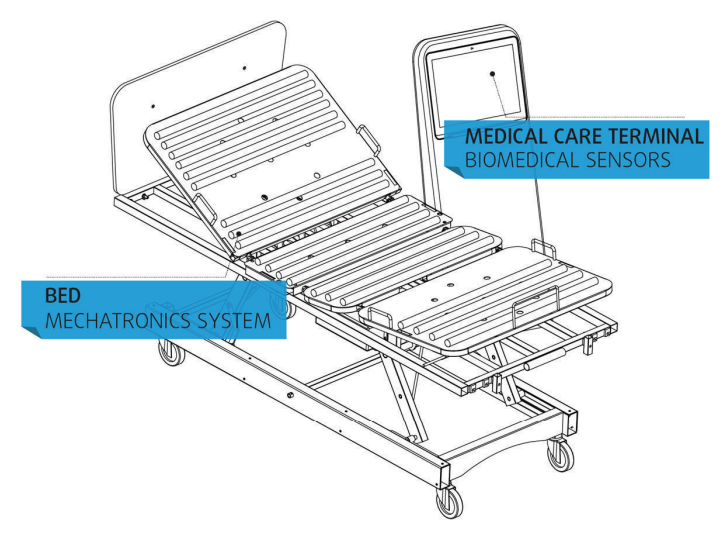

Figure 8: Bed with the MCT system [13, 14].

(i) The temperature sensor monitors the environment temperature. The sensor output values are in degrees centigrade, so there is no need for any preprocessing.

(ii) The light sensor measures the light intensity of the environment (lux), using a LDR (light dependent resistor) and an analog signal, and thus the output values must be preprocessed. There are three categories of light intensity considered: high brightness ( 0 to $1 / 4$ full scale), middle light (from $1 / 4$ full scale to $1 / 2$ full scale), and darkness (over $1 / 2$ full scale).

(iii) The air quality sensor presents a value which is proportional to the air quality measured by the sensor.

(iv) The carbon monoxide (CO) sensor is suitable for detecting concentrations of $\mathrm{CO}$ in air. The MQ-7 version can detect $\mathrm{CO}$ concentrations anywhere within 20-2000 ppm.

The communication between the PC and the MCT system is performed through XBee Modules. Figure 11 shows the E-Health shield placed together with the wireless shield modules.

4.2. MCT User Interface in LabVIEW. The user interface was developed in LabVIEW (Figure 12) [12, 26-29]. The interface allows a friendly interaction with the user.

The interface has four sections: the first one corresponds to the system welcome page, the second one is dedicated to the monitoring of the environmental variables profiles (room temperature, brightness, and air quality), the third section shows the patient data that can be accessed through the biomedical sensors placed on the patient, and, finally, the fourth section allows the remote communication with a medical specialist.

From the interface, the measured data can be recorded in MS Excel, allowing further analysis.

In Figure 13, an environmental sensor interface, namely, the light sensor, is shown. The interface includes a light emitting diode warning when there is a lack of light in the room.

Figure 14 shows the information regarding the respiration sensor: the measured values of the breath sensor and the 


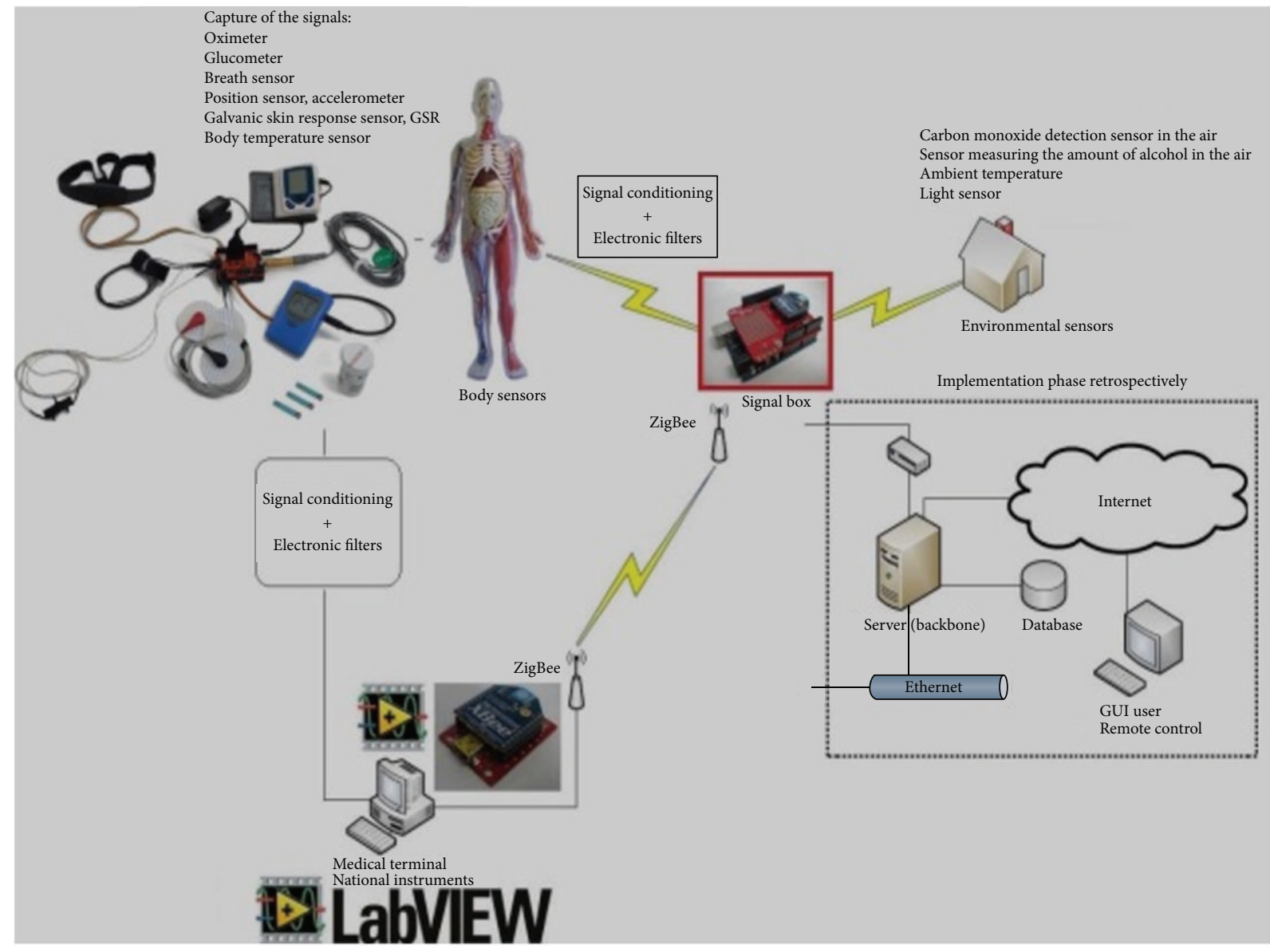

FIGURE 9: Block system diagram [14].

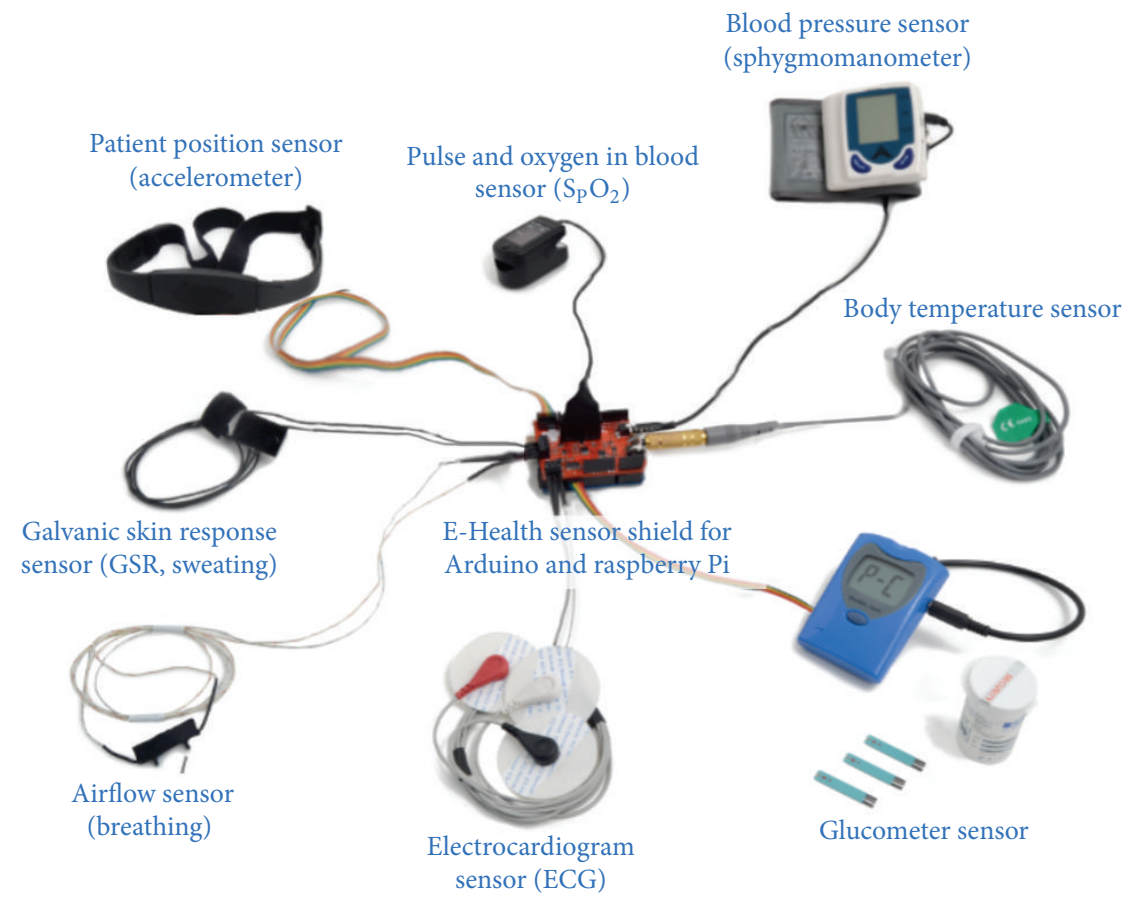

FigURE 10: Cooking development kit used in the MCT (adapted from [12]). 

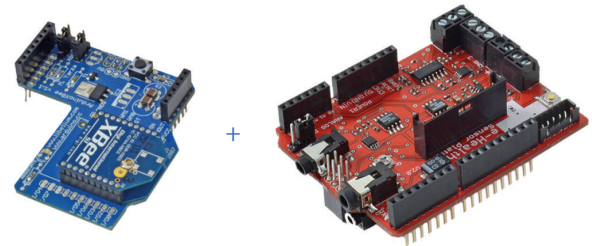

FIgURE 11: XBee shield placed on the plate E-Health and the set on the Arduino (adapted from [12]).

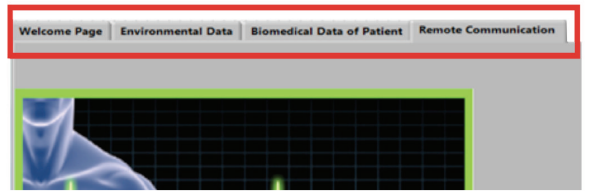

FIGURE 12: MCT interface in LabVIEW-welcome page [14].

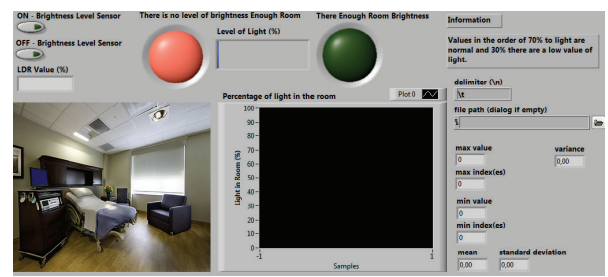

FIgURE 13: LabVIEW interface for environmental sensors-light sensor [14].

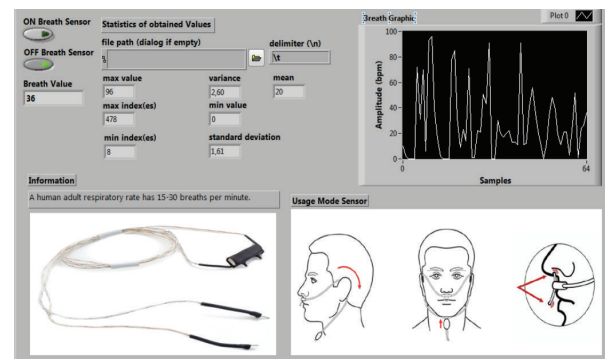

FIGURE 14: LabVIEW interface for biomedical sensors-respiration sensor [14].

information related to the desired values allowing some preliminary diagnosis.

In order to enable the remote access to MCT, a web page was developed using the Web Publishing Tool from LabVIEW.

Through this remote access, the caregiver (or even the patient) can communicate with a health professional if necessary (Figure 15), using videoconference applications as Skype, as example. It is worth mentioning that the remote access is allowed under login and password, through a dedicated webpage developed in html and JavaScript, for security.

The system is also able to send an e-mail to the caregiver, nurse, or doctor with the patient's data, when there is measured value outside the recommended parameters.

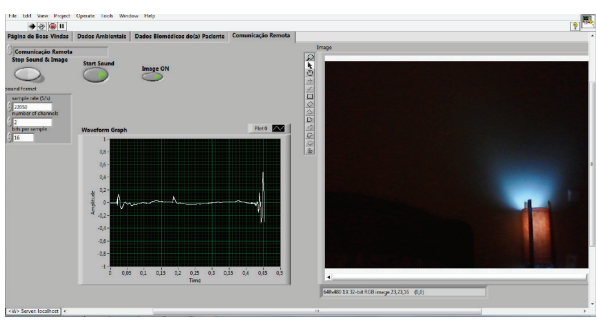

FIGURE 15: Interface created in LabVIEW for remote communication [14].

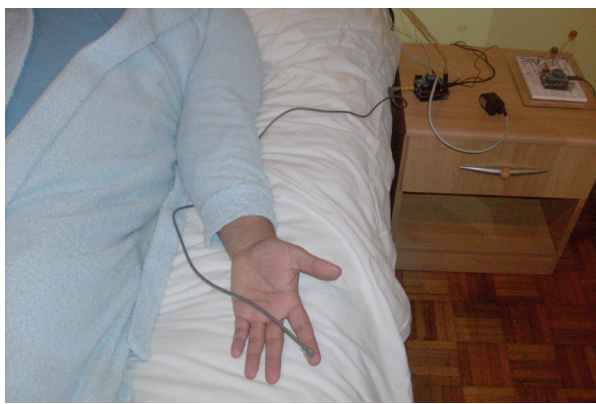

FIgURE 16: Placement of the body temperature sensor in the patient [14].

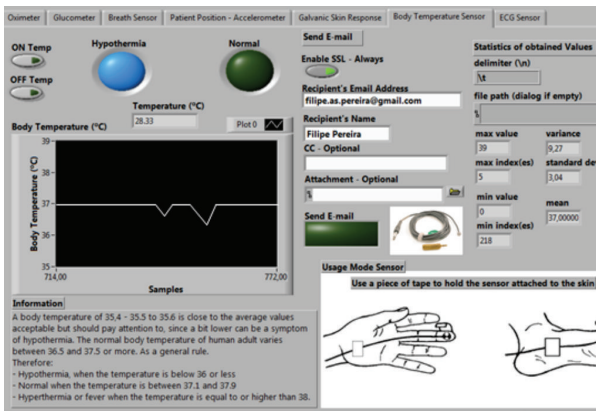

FIGURE 17: Obtaining the body temperature profile in the MCT [14].

\section{Experimental Results}

In this section, some results obtained with the MCT regarding physiological and environmental data are presented.

5.1. Biomedical Sensors. The system was tested with two healthy persons: (a) a 28 -year-old male, measuring $1.73 \mathrm{~m}$ and weighing $62 \mathrm{~kg}$; (b) a 31-year-old female, measuring $1.76 \mathrm{~m}$ and weighing $79 \mathrm{~kg}$.

The first test was carried out to obtain the value of body temperature. Figure 16 refers to the sensor placement and Figure 17 shows the user interface where the temperature is acquired through wireless communication and registered in a chart.

The second test was carried out to obtain the value of the galvanic skin response of the patient. Figures 18 and 19 show the sensor positioning in the patient and the corresponding user interface, respectively. 


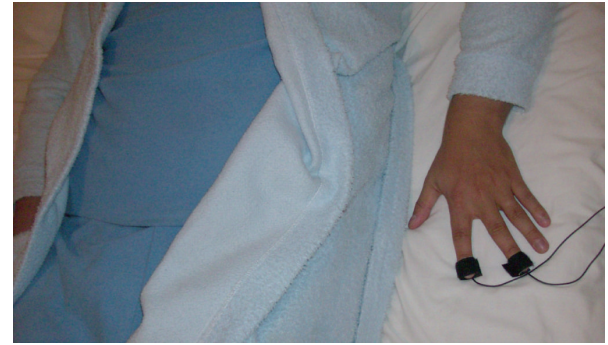

FIGURE 18: Placing the galvanic skin response sensor in the patient [14].

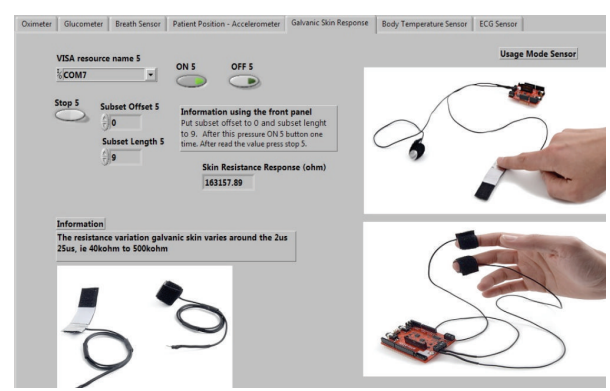

FIGURE 19: Obtaining the value of the galvanic skin response in the MCT [14].

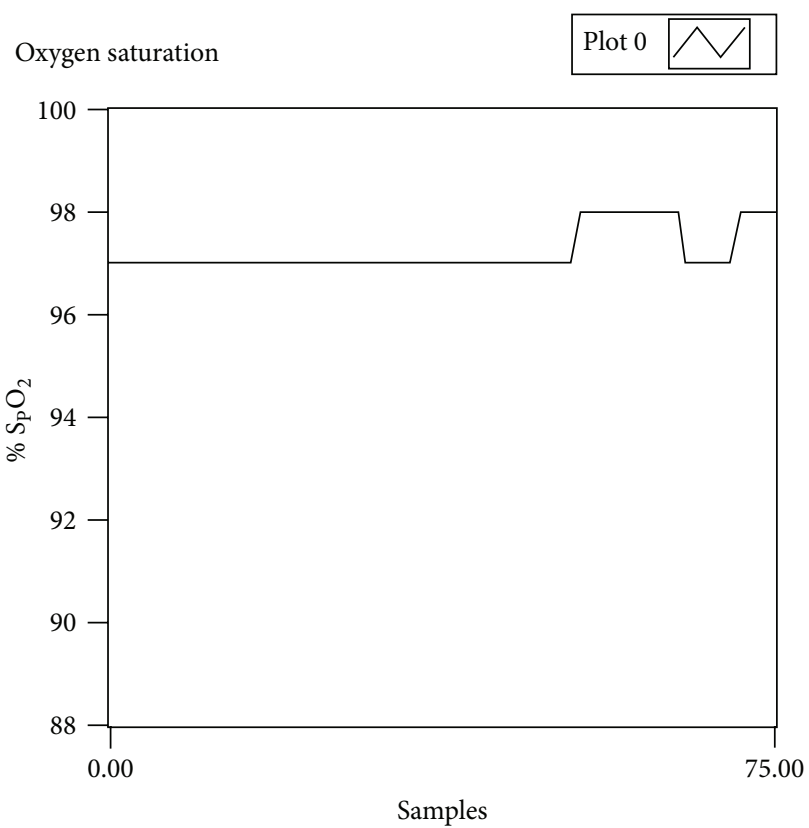

FIGURE 20: Oxygen saturation in the MCT for Patient 1 obtained in LabVIEW.

Figures 20 and 21 show the obtained values of oxygen saturation for the two patients, respectively. Blood oxygenation level is associated with cardiovascular fitness, and raising oxygenated blood coloration in human faces increases perceived health [30-34].

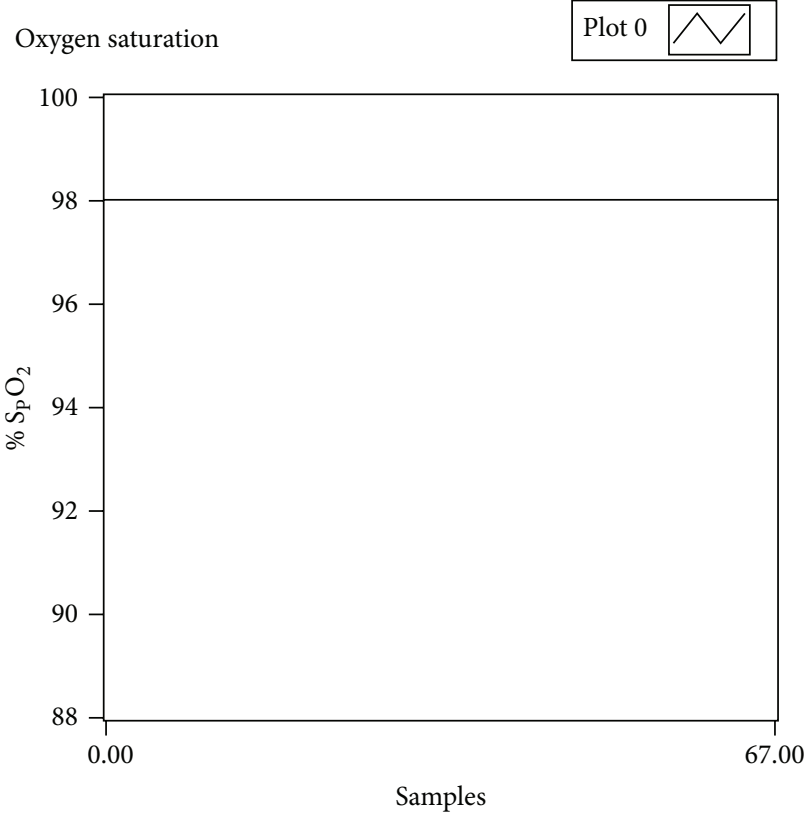

FIGURE 21: Oxygen saturation in the MCT for Patient 2 obtained in LabVIEW.

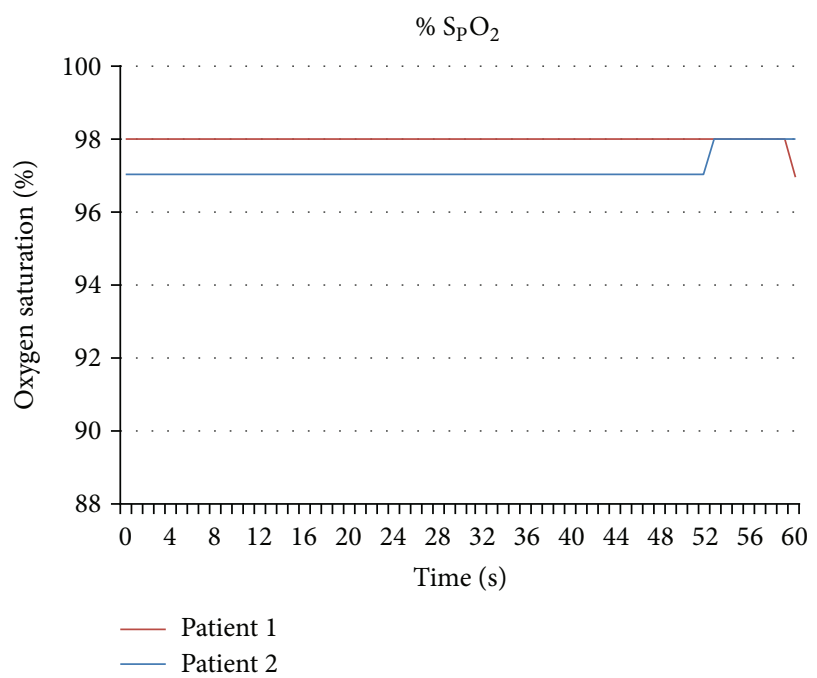

FIgURE 22: Comparison of oxygen saturation profiles for the two patients.

Figures 22 and 23 show a comparison of the oxygen saturation and the body temperature profiles for the two patients, respectively.

Patient 2 has muscular dystrophy hands, known as Becker muscular dystrophy. This dystrophy causes instant temperature changes in the affected area and hence the changing of skin temperature in the said patient.

5.2. Environmental Sensors. Figure 24 shows the room temperature profile registered in the MCT interface.

5.3. Remote Communication. To remotely access MCT interface, the user must enter the login and password to access 


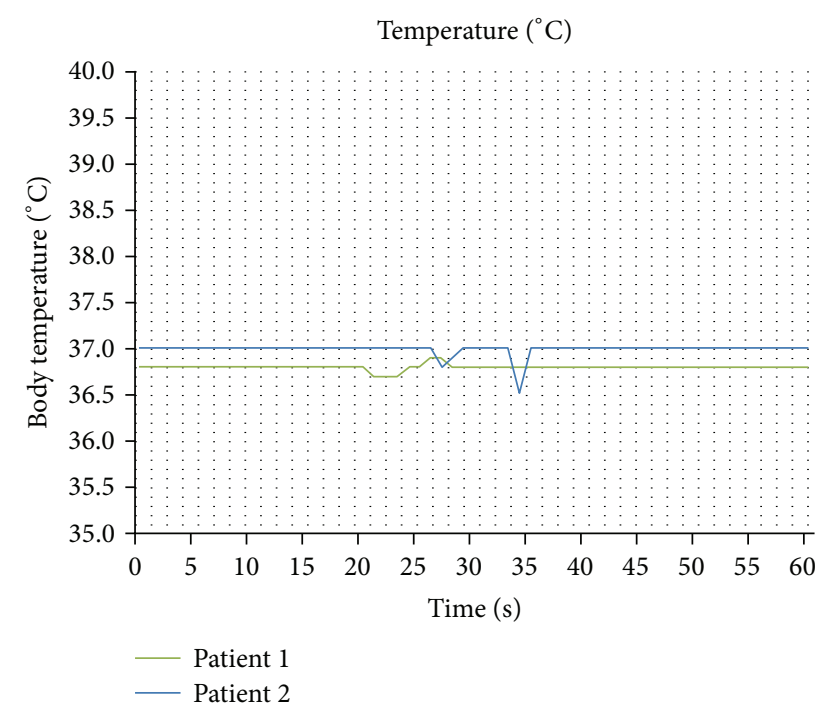

FIGURE 23: Comparison of the body temperature profiles for the two patients.

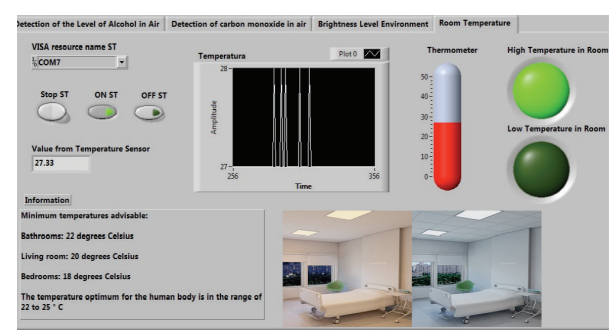

FIgURE 24: Room temperature profile in MCT [14].

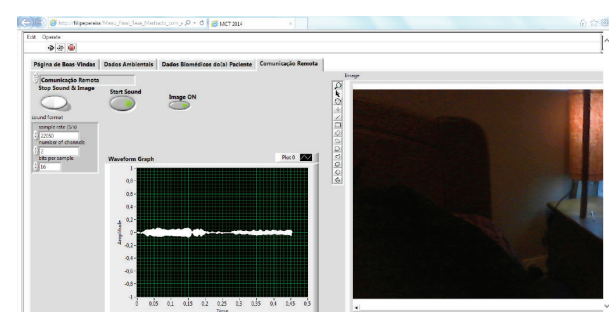

FIGURE 25: Remote communication with image and sound [14].

the patient's information. Figure 25 shows the access to room environment registering sound and patient image.

\section{Conclusions and Future Work}

This work describes the development of a Medical Care Terminal (MCT), to be included in a mechatronic system, able to allow the remote monitoring of bedridden patients.

The main objective of the work is to provide the caregiver with the ability to monitor, in real time, the patient and the environment he/she is in. It also allows the possibility of remote communication under authentication. The biomedical sensors included in the developed system allow the following measures: (i) Body temperature (BT).

(ii) Galvanic skin resistance (GSR).

(iii) Electrocardiogram (ECG).

(iv) Level of oxygen.

(v) Body position.

(vi) Breath.

The environmental sensors included in the system allow the following measures:

(i) Level of alcohol in the air.

(ii) Carbon monoxide level in the air.

(iii) Brightness.

(iv) Temperature.

This system has three main advantages in comparison with the commercial available ones, listed as follows:

(i) It is a user-friendly interface, easy to use by a single elderly person as there are provided step-by-step instructions of handling the software and the application of sensors. In short, it does not require specialized knowledge to be properly operated.

(ii) It is adapted to the needs of a specific patient, as the system can be configured in function of the measurements required for that specific patient. Moreover, other sensors can be easily included due to modular architecture of the system, as well as the actions provided as a result of the measurements obtained.

(iii) It is a low cost solution, with an estimated consumer price below $1 \mathrm{KE}$, in order to be affordable even for low budget consumer markets.

MCT was tested in laboratorial environment with two healthy persons. This system is also prepared for adaptation of

(i) wireless transmission of the sensors, making the system less invasive and more convenient to use, depending on the choice of the final user's family;

(ii) the possibility of adding of new functionalities (e.g., smartphone and tablet interfaces).

This is an option of configuration that can be chosen by the final user's family.

To accomplish the objectives of the overall project, MCT is part of the mechatronic system to assist bedridden patients.

\section{Competing Interests}

The authors declare that they have no competing interests.

\section{Acknowledgments}

This research was funded by Portuguese Foundation for Science and Technology (FCT) through the R\&D Project FCOMP-01-0124-FEDER-022601 (reference FCT PTDC/ CPE-PEC/122329/2010). This work has also been supported by FCT in the scope of the project: PEst-UID/ CEC/00319/2013. 


\section{References}

[1] O. Geman, C.-O. Turcu, and A. Graur, "Parkinson's disease screening tools using a fuzzy expert system," Advances in Electrical and Computer Engineering, vol. 13, no. 1, pp. 41-46, 2013.

[2] Social Security, by Govern of Portugal, (Portuguese), http:// www4.seg-social.pt/documents/10152/13327/acolhimento_residencial_pessoas_deficiencia.

[3] S. Chernbumroong, S. Cang, A. Atkins, and H. Yu, "Elderly activities recognition and classification for applications in assisted living," Expert Systems with Applications, vol. 40, no. 5, pp. 1662-1674, 2013.

[4] International Labour Organization, by International Labour Organization, 2015, http://www.ilo.org/public/portugue/region/ eurpro/lisbon/pdf/cit102_rel4_emprego_prtsocial_demografico .pdf.

[5] D. Cowan and A. Turner-Smith, The Role of Assistive Technology and Alternative Models of Care for Elderly People, Centre for Rehabilitation and Engineering, Kings College London, London, UK, 1998.

[6] Ortopedia Carlita, by Grupo Carlita, 2015 (Portuguese), http:// www.ortopediacarlita.com.pt/index.php?\&vmcchk=1.

[7] F. Felisberto, R. Laza, F. Fdez-Riverola, and A. Pereira, "A distributed multiagent system architecture for body area networks applied to healthcare monitoring," BioMed Research International, vol. 2015, Article ID 192454, 17 pages, 2015.

[8] PLUX -wireless biosignals, by PLUX S.A., March 2015, https:// www.behance.net/gallery/4111667/bioPLUX-clinical.

[9] Avalue, by Avalue Technology Inc, 2015, http://www.avalue .com.tw/en/index.aspx.

[10] T. Wessa, M. Rapp, and H. Ache, "New immobilization method for SAW-biosensors: covalent attachment of antibodies via CNBr," Biosensors and Bioelectronics, vol. 14, no. 1, pp. 93-98, 1999.

[11] M. Merah, A. Ouamri, A. Naït-Ali, and M. Keche, "Fault tolerant neural network for ECG signal classification systems," Advances in Electrical and Computer Engineering, vol. 11, no. 3, pp. 17-24, 2011.

[12] Cooking Hacks, by Libelium, March 2015, http://www.cookinghacks.com/.

[13] S.-W. Peng, F.-L. Lian, and L.-C. Fu, "Mechanism design and mechatronic control of a multifunctional test bed for bedridden healthcare," IEEE/ASME Transactions on Mechatronics, vol. 15, no. 2, pp. 234-241, 2010.

[14] F. Pereira, V. Carvalho, F. Soares et al., "Development of a mechatronic system for bedridden people support," in Proceedings of the 5th International Conference on Innovations, Recent Trends and Challenges in Mechatronics, Mechanical Engineering and New High-Tech Products Development (MECAHITECH '13), Bucharest, Romania, September 2013.

[15] K. J. Reynolds, J. T. B. Moyle, L. B. Gale, M. K. Sykes, and C. E. W. Hahn, "In vitro performance test system for pulse oximeters," Medical and Biological Engineering and Computing, vol. 30, no. 6, pp. 629-635, 1992.

[16] R. Haahr, Reflectance pulse oximetry sensor for the electronic patch [M.S. dissertation], Technical University of Denmark, Kongens Lyngby, Denmark, 2006.

[17] K. H. Shelley, "Photoplethysmography: beyond the calculation of arterial oxygen saturation and heart rate," Anesthesia \& Analgesia, vol. 105, no. 6, pp. S31-S36, 2007.

[18] Biology Corner by Biology Corner, 2015, http://www.biologycorner.com/anatomy/circulatory/ecg.html.
[19] J. P. Abenstein and W. J. Tompkins, "A new data-reduction algorithm for real-time ECG analysis," IEEE Transactions on Biomedical Engineering, vol. 29, no. 1, pp. 43-48, 1982.

[20] Galura basa, by Galura basa, March 2015, http://galura-basa .blogspot.pt/2011/06/normal-and-abnormal-ecg-readings.html.

[21] M. L. Ahlstrom and W. J. Tompkins, "Digital filters for realtime ecg signal processing using microprocessors," IEEE Transactions on Biomedical Engineering, vol. 32, no. 9, pp. 708-713, 1985.

[22] Z. Yuan, J. H. Kim, and J. D. Cho, "Adaptive sampling for ECG detection based on compression dictionary," Journal of Semiconductor Technology and Science, vol. 13, no. 6, pp. 608616, 2013.

[23] M. Fira, L. Goras, G. Asachi, Institute of Computer Science, and Romanian Academy, "A new method for EEG compressive sensing," Advances in Electrical and Computer Engineering, vol. 12, no. 4, pp. 71-76, 2012.

[24] M. Fira, L. Goraş, C. Barabasa, and N. Cleju, "On ECG compressed sensing using specific overcomplete dictionaries," Advances in Electrical and Computer Engineering, vol. 10, no. 4, pp. 23-28, 2010.

[25] C. Levkov, G. Mihov, R. Ivanov, I. Daskalov, I. Christov, and I. Dotsinsky, "Removal of power-line interference from the ECG: a review of the subtraction procedure," BioMedical Engineering OnLine, vol. 4, article 50, 2005.

[26] Sparkfun, by Spark Fun Electronics, http://www.sparkfun.com/ products $/ 8880$.

[27] T. Du and C. Fang, "Sensors state monitoring based on labview and wireless nodes," Procedia Engineering, vol. 15, pp. 26392643, 2011

[28] T. Yukawa, Y. Kuramochi, T. Takahashi, and K. Takahashi, "Nursing-care system for bedridden patients with electric wheelchair, lift, portable bath, mobile robot and portable toilet," International Journal of Engineering and Innovative Technology (IJEIT) , vol. 2, no. 5, 2012.

[29] S. Silva, H. Martins, A. Valente, and S. Soares, "A bluetooth approach to diabetes sensing on ambient assisted living systems," Procedia Computer Science, vol. 14, pp. 181-188, 2012.

[30] Z.-B. Zhou, W.-J. Liu, and C.-C. Liu, "Studies on the biomedical sensor techniques for real-time and dynamic monitoring of respiratory gases, $\mathrm{CO}_{2}$ and $\mathrm{O}_{2}$," Sensors and Actuators, $\mathrm{B}$ : Chemical, vol. 65, no. 1-3, pp. 35-38, 2000.

[31] T. Watanabe, A. Mikami, T. Kumano-Go et al., "The relationship between esophageal pressure and apnea hypopnea index in obstructive sleep apnea-hypopnea syndrome," Sleep Research Online, vol. 3, no. 4, pp. 169-172, 2000.

[32] T. Penzel, K. Kesper, and H. Becker, "Biosignal monitoring and recording," in Information Technology Solutions for Healthcare, pp. 288-301, Springer, London, UK, 2006.

[33] V. Hollis, Non-Invasive monitoring of brain tissue temperature by NearInfrared spectroscopy [Ph.D. thesis], University College London, London, UK, 2002.

[34] I. Hlimonenko, K. Meigas, and R. Vahisalu, "Waveform analysis of peripheral pulse wave detected in the fingertip with photoplethysmograph," Measurement Science Review, vol. 3, no. 2, pp. 49-52, 2003. 


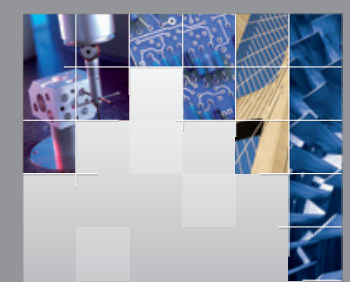

\section{Enfincering}
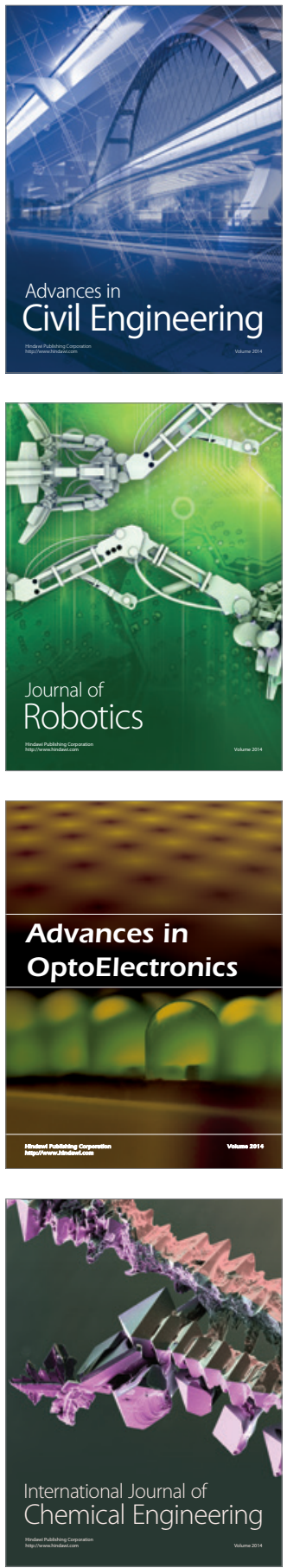

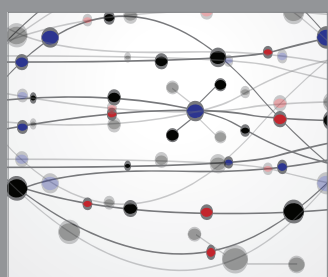

The Scientific World Journal

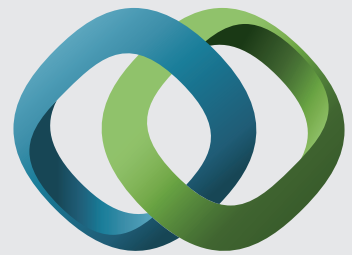

\section{Hindawi}

Submit your manuscripts at

http://www.hindawi.com
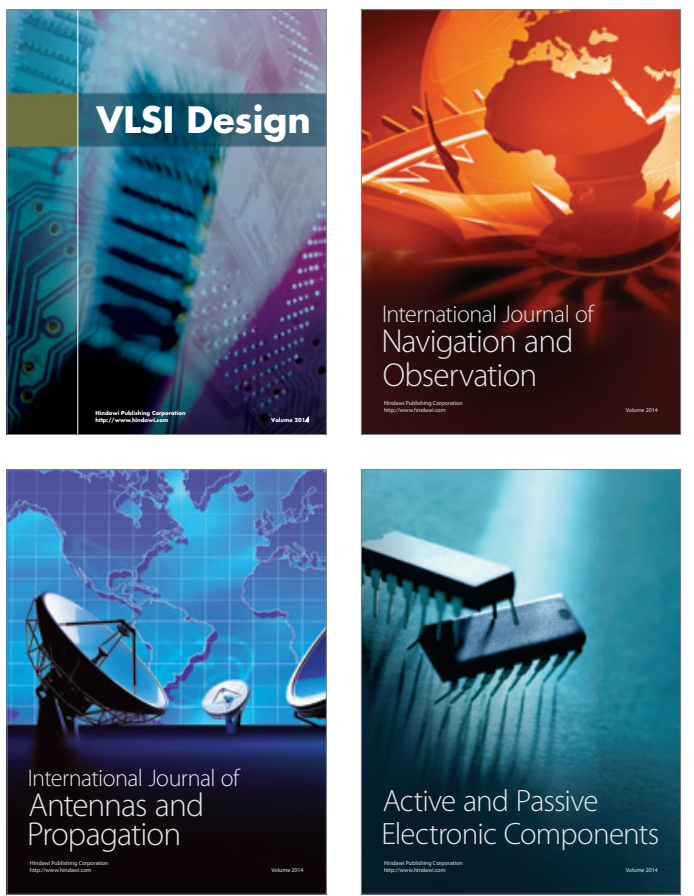
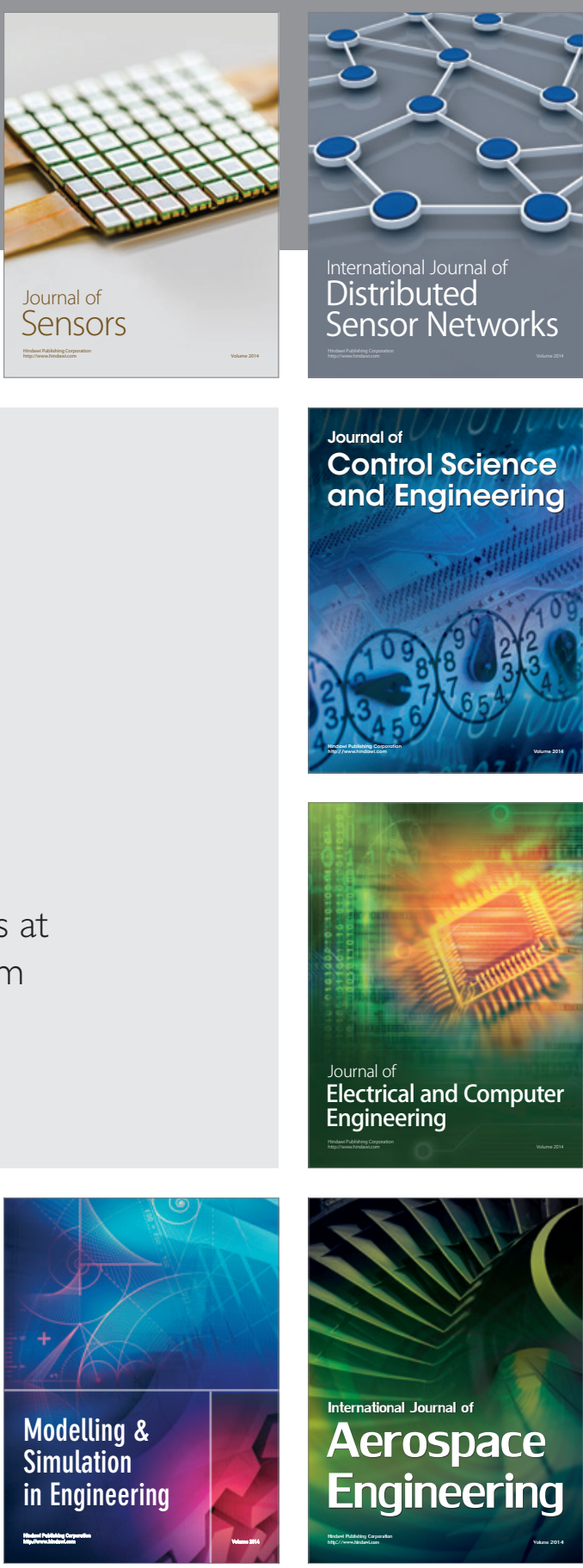

International Journal of

Distributed

Sensor Networks

Journal of

Control Science

and Engineering
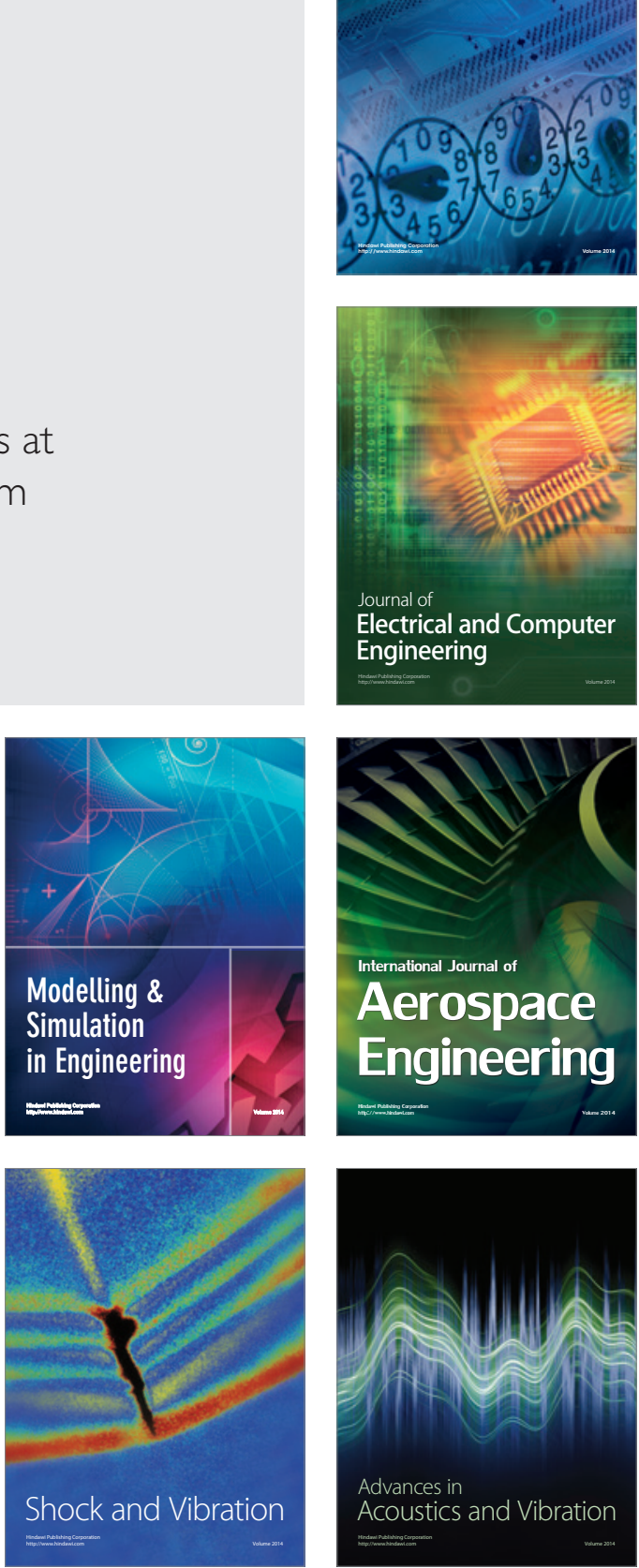